\title{
An application of Huber model on the effect of psychological empowerment of employees on organizational learning
}

\author{
Mahdie Mirzaiefar*
}

Graduate Master of Business management, Borujerd Branch, Islamic Azad University, Borujerd, Iran

\begin{tabular}{l}
\hline C H R O N I C L E \\
\hline Article history: \\
Received October 30, 2013 \\
Received in revised format \\
30 November 2013 \\
Accepted 9 January 2014 \\
Available online \\
January 202014 \\
\hline Keywords: \\
Psychological empowerment \\
Learning - organizational \\
learning \\
Knowledge distribution \\
Knowledge interpretation \\
Knowledge achievement \\
Organizational memory
\end{tabular}
A B S T R A C T

\begin{abstract}
The purpose of this descriptive-survey study is to determine the effect of psychological empowerment of employees on organizational learning based on Huber model. The study selects a sample of 54 people randomly from 499 regular employees of a Gas distribution firm located in province of Lorestan, Iran. For collecting data, two questionnaires of Huber organizational learning and psychological empowerment based on Spreitzer (1995) model [Spreitzer, G. M. (1995). Psychological empowerment in the workplace: Dimensions, measurement, and validation. Academy of management Journal, 38(5), 1442-1465.] are used. Cronbach's alpha coefficients of organizational and psychological empowerment questionnaires are 0.706 and 0.92, respectively. SPSS software and linear regression test, binomial test, Pearson correlation test, and Friedman tests are used to analyze data and examine the hypotheses. The results of the data analysis show that psychological empowerment of employees could influence on organizational learning aspects in organization, significantly.
\end{abstract}

\section{Introduction}

For years, there have been different attempts to discuss various issues associated with empowering employees (Menon, 1999; Corsun \& Enz, 1999). Zimmerman (1992, 1995), for instance, discussed various aspects of psychological empowerment and concluded that the development of a universal and global measure of psychological empowerment may not necessarily be a feasible or appropriate objective. Bhatnagar (2007) determined various predictors of organizational commitment in India by discussing strategic human resources roles, organizational learning capability and psychological empowerment. Laschinger et al. (2001) investigated the effects of structural and psychological empowerment on job strain in nursing work settings. Egan et al. (2004) studied the impacts of organizational learning culture and job satisfaction on motivation to transfer learning and turnover intention and reported that empowering employees could strongly influence on employees' job *Corresponding author.

E-mail addresses: azad.amirali@yahoo.com (M. Mirzaiefar) 
satisfaction. Spreitzer (1996) performed a set of hypotheses based on emerging theory on highinvolvement systems and explained expected relationships between social structural characteristics at the level of the work unit and feelings of empowerment. In this study, a work unit with little role ambiguity, strong sociopolitical support, access to information, and a participative unit climate was related to managerial perceptions of empowerment. Liden et al. (2000) reported that work satisfaction could be described largely by job characteristics through empowerment but leader-member exchange and team-member exchange combined with job characteristics and empowerment could explain variation in organizational commitment and job performance. Zhang and Bartol (2010) investigated the linking empowering leadership and employee creativity by studying the effect of psychological empowerment, intrinsic motivation, and creative process engagement.

\section{The proposed study}

\subsection{Research hypotheses}

First hypothesis: Psychological empowerment of employees influences on organizational memory in organizational level.

Second hypothesis: Psychological empowerment of employees influences on knowledge obtaining.

Third hypothesis: Psychological empowerment of employees influences on knowledge distribution.

Fourth hypothesis: Psychological empowerment of employees influences on knowledge interpretation.

\subsection{Research Methodology}

The purpose of this descriptive-survey study is to determine the effect of psychological empowerment of employees on organizational learning based on Huber model. The study has been accomplished among regular employees of Gas distribution company in province of Lorestan, Iran. The sample size is calculated as follows,

$$
n=\frac{N \times z_{\alpha / 2}^{2} \times p \times q}{\varepsilon^{2} \times(N-1)+z_{\alpha / 2}^{2} \times p \times q},
$$

where $N$ is the population size, $p=1-q$ represents the yes/no categories, $z_{\alpha / 2}$ is CDF of normal distribution and finally $\varepsilon$ is the error term. Since we have $p=0.5, z_{\alpha / 2}=1.96$ and $N=499$, the number of sample size is calculated as $n=54$. The study selects a sample of 54 people randomly from 499 regular employees of a Gas distribution firm located in province of Lorestan, Iran. For collecting data, two questionnaires of Huber organizational learning (Huber, 1991) and psychological empowerment based on Spreitzer (1995) model are used. Cronbach's alpha coefficient of organizational and psychological empowerment questionnaires are 0.706 and 0.92, respectively. SPSS software and linear regression test, binomial test, Pearson correlation test, and Friedman tests are used to analyze data and examine the hypotheses. Table 1 and Table 2 demonstrate some descriptive information associated with this study.

\section{Table 1}

Description of frequency percent of answers to dependent variables

\begin{tabular}{|c|c|c|c|c|c|c|c|c|}
\hline & \multicolumn{2}{|c|}{ Knowledge interpretation } & \multicolumn{2}{|c|}{ Knowledge distributions } & \multicolumn{2}{|c|}{ Knowledge obtaining } & \multicolumn{2}{|c|}{ Organization memory } \\
\hline & Freq. & $\%$ & Freq. & $\%$ & Freq. & $\%$ & Freq. & $\%$ \\
\hline Very little & 17 & 11.33 & 65 & 26 & 54 & 27 & 22 & 22 \\
\hline Little & 27 & 18 & 81 & 32.4 & 48 & 24 & 20 & 20 \\
\hline Average & 57 & 38 & 65 & 26 & 53 & 26.5 & 33 & 33 \\
\hline High & 45 & 30 & 33 & 13.2 & 39 & 19.5 & 22 & 22 \\
\hline Very high & 4 & 2.67 & 6 & 2.4 & 6 & 3 & 3 & 3 \\
\hline Total sum & 150 & 100 & 2500 & 100 & 200 & 100 & 100 & 100 \\
\hline
\end{tabular}


Table 2

Description of frequency percent of answers to independent variables

\begin{tabular}{lcc}
\hline & & Psychological empowerment \\
\cline { 2 - 3 } & Frequency & Frequency percent \\
\hline Very little & 101 & 10.63 \\
little & 143 & 15.05 \\
Average & 217 & 22.84 \\
High & 369 & 32.84 \\
Very high & 120 & 12.63 \\
Total sum & 950 & 100 \\
\hline
\end{tabular}

\section{The results}

3.1 First hypothesis: Psychological empowerment of employees influences on organizational memory in organizational level.

$\mathrm{H}_{0}$ : psychological empowerment of employees has no effect on organizational memory.

$\mathrm{H}_{1}$ : psychological empowerment of employees has effect on organizational memory.

Table 3 demonstrates the results of our findings on testing the first hypothesis of this survey.

Table 3

Regression model of effect of employee's psychological empowerment on organizational memory

\begin{tabular}{lccccc}
\hline Variables & B (coefficient) & Standard errors & Beta & T & Significant level \\
\hline Constant value & 1.88 & 0.530 & & 3.55 & 0.001 \\
Current empowerment & 0.325 & 0.287 & 0.287 & 2.07 & 0.043 \\
\hline
\end{tabular}

Correlation coefficient: 0.287

Determine coefficient $\left(\mathrm{R}^{2}\right): 0.82$

F (probable): 4.3(0.043)

Dependent variable: organizational memory

According to Table 3, we observe that the correlation coefficient is 0.287 , which shows there is a positive relationship between dependent and independent variables. The result also shows that significant level of $t$ test is less than $5 \%$ for psychological empowerment of employees so it can participate in the equation. On the other hand, dependent variable is effective.

$$
y=a+\left(b_{1} x_{1}\right)
$$

Organizational memory $=1.88+0.325$ (psychological empowerment) and it is observed that psychological empowerment of employees influences positively on organizational memory by 0.325 unit. Therefore, with 95\% confidence we can say psychological empowerment of employees influences on organizational memory.

3.2 Second hypothesis: Psychological empowerment of employees influences on knowledge obtaining.

$\mathrm{H}_{0}$ : Psychological empowerment of employees has no effect on knowledge obtaining.

$\mathrm{H}_{1}$ : Psychological empowerment of employees has effect on knowledge obtaining.

\section{Table 4}

Regression model of effect of employee's psychological empowerment on knowledge obtaining

\begin{tabular}{lccccc}
\hline Variables & B (coefficient) & Standard errors & Beta & T & Significant level \\
\hline Constant value & 1.34 & 0.472 & & 2.85 & 0.006 \\
Current empowerment & 0.302 & 0.140 & 0.297 & 2.15 & 0.036 \\
\hline Con
\end{tabular}

Correlation coefficient: 0.297

Determine coefficient: $\left(\mathrm{R}^{2}\right): 0.088$

F (probable): 4.65(0.036)

Dependent variable: knowledge obtaining 
Table 4 shows that obtained correlation coefficient is 0.297 , which illustrates there is a positive relationship between dependent and independent variables. Table 4 also shows that significant level of $t$ test for psychological empowerment of employees is less than 5\%. Therefore, it can be used in the equation on the other hand. It has effect on dependent variable.

$$
y=a+\left(b_{1} \times x_{1}\right)
$$

Knowledge obtaining $=1.34+0.302$ (psychological empowerment) is observed. The psychological empowerment of employees influences on knowledge obtaining by 0.302 units. As a result, with 95\% confidence, we can say that psychological empowerment of employees has effect on knowledge obtaining.

3.3 Third hypothesis: Psychological empowerment of employees influences on knowledge distribution.

$\mathrm{H}_{0}$ : psychological empowerment of employees has no effect on knowledge distribution.

$\mathrm{H}_{1}$ : psychological empowerment of employees has effect on knowledge distribution.

\section{Table 5}

Regression model of effect of employee's psychological empowerment on knowledge distribution

\begin{tabular}{lccccc}
\hline Variables & B (coefficient) & Standard errors & Beta & T & Significant level \\
\hline Constant value & 0.746 & 0.544 & & 1.37 & 0.177 \\
Current empowerment & 0.528 & 0.161 & 0.427 & 3.27 & 0.002 \\
\hline
\end{tabular}

Correlation coefficient: 0.427

Determine coefficient: $\left(\mathrm{R}^{2}\right): 0.183$

F (probable): 10.73(0.002)

Dependent variable: knowledge distribution

As we can observe from the results of Table 5, the correlation coefficient is 0.427 , which shows that there is a positive correlation between dependent and independent variables and significant level of $t$ test is less than $1 \%$ for psychological empowerment of employees. Therefore, it can participate in the equation. On the other hand, it has effect on dependent variable.

$$
y=a+\left(b_{1}+x_{1}\right)
$$

Knowledge distribution $=0.528$ (psychological empowerment)

It is observed that psychological empowerment of employees influence on knowledge distribution in 0.528. As a result, with confidence of $99 \%$ we can say psychological empowerment of employees has meaningful effect on knowledge distribution.

3.4. Fourth hypothesis Psychological empowerment of employee influences on knowledge interpretation.

$\mathrm{H}_{0}$ : psychological empowerment of employees has no effect on knowledge interpretation.

$\mathrm{H}_{1}$ : psychological empowerment of employees has effect on knowledge interpretation.

\section{Table 6}

Regression model of effect of employee's psychological empowerment on knowledge interpretation

\begin{tabular}{lccccc}
\hline Variables & B (coefficient) & Standard errors & Beta & T & Significant level \\
\hline Constant value & 0.881 & 0.598 & & 1.47 & 0.147 \\
Current empowerment & 0.537 & 0.177 & 0.401 & 3.03 & 0.004 \\
\hline
\end{tabular}

Correlation coefficient: 0.401

Determine coefficient: $\left(\mathrm{R}^{2}\right): 0.161$

F (probable): 9.2(0.004)

Dependent variable: knowledge interpretation 
Table 6 shows that obtained correlation is 0.401 , which means there is a positive correlation between dependent and independent variables. Table 6 also shows that significant level of $t$ test is less than 1\% for psychological empowerment of employees. Therefore, it can participate in the equation. On the other hand, it has effect on dependent variable.

$$
y=a+\left(b_{1} x_{1}\right)
$$

Knowledge interpretation $=0.537$ (psychological empowerment)

It is observed that psychological empowerment of employee influences on knowledge interpretation by 0.537 units. As a result, with $99 \%$ confidence we can say that psychological empowerment of employees has effect on knowledge interpretation.

Table 7

The results of binomial test to estimate the research variables

\begin{tabular}{|c|c|c|c|c|c|c|}
\hline & & Classification & Number & Ratio & Total ratio & Significant Level \\
\hline \multirow{3}{*}{ Organizational memory } & Equal to 3 and less & $3<=$ & 26 & 0.52 & 0.50 & 0.888 \\
\hline & More than 3 & $3>$ & 24 & 0.48 & & \\
\hline & Sum & & 50 & 1 & & \\
\hline \multirow{3}{*}{ Knowledge obtaining } & Equal to 3 and less & $3<=$ & 44 & 0.88 & 0.50 & 0.000 \\
\hline & More than 3 & $3>$ & 6 & 0.12 & & \\
\hline & Sum & & 50 & 1 & & \\
\hline \multirow{3}{*}{ Knowledge distribution } & Equal to 3 and less & $3<=$ & 34 & 0.68 & 0.50 & 0.015 \\
\hline & More than 3 & $3>$ & 16 & 0.32 & & \\
\hline & Sum & & 50 & 1 & & \\
\hline \multirow{3}{*}{ Knowledge interpretation } & Equal to 3 and less & $3<=$ & 35 & 0.7 & 0.50 & 0.007 \\
\hline & More than 3 & $3>$ & 15 & 0.30 & & \\
\hline & Sum & & 50 & 1 & & \\
\hline \multirow{3}{*}{ Empowerment } & Equal to 3 and less & $3<=$ & 15 & 0.30 & 0.50 & 0.007 \\
\hline & More than 3 & $3>$ & 35 & 0.7 & & \\
\hline & Sum & & 50 & 1 & & \\
\hline
\end{tabular}

As we can observe from the results of Table 7, three knowledge components along with empowerment are statistically significance but organizational memory is not significance. Finally, we have used Freedman test to rank different components of the survey and the results are summarized in Table 8 as follows.

\section{Table 8}

The results of Friedman test for ranking organizational learning aspects

\begin{tabular}{ll}
\hline Component & Value \\
\hline Organizational memory & 2.92 \\
Knowledge obtaining & 2.15 \\
Knowledge distribution & 2.34 \\
Knowledge interpretation & 2.59 \\
\hline Number & 50 \\
Chi-Square amount & 11.18 \\
Freedom degree & 3 \\
Significant level & 0.011
\end{tabular}

According to the results of Table 8, it is observed that significant level of fried man test is less than $5 \%$. Therefore, there is a difference between various aspects of organization learning in terms on ranking. In other words, organizational memory is the most important factor followed by knowledge interpretation, knowledge distribution and knowledge obtaining.

\section{Conclusion and suggestions}

The present research attempted to consider the effect of empowerment on organizational learning. In terms of empowerment, psychological approach is important and organizational learning variable has 
been considered by characteristics of Huber model including knowledge, information distribution, information interpretation and organizational memory. With regard to statistical analysis, all four hypotheses have been confirmed, and psychological empowerment variable has had significant effect on various aspects of organizational learning. Based on the results, empowerment of employees in mentioned company by considering the psychological empowerment component's has had positive effect on learning in organization level and it has had effect on collecting, interpretation, process, recording and saving data and information in organization and makes current information in mentioned company and can be applied as advantage factor of company.

It seems that empowering employees has to be accomplished to increase their motivation in working harder and contributing more to their job. Therefore, it is suggested to perform some studies on individuals' characteristics and their abilities to examine their preparation on for acceptance of empowerment program. In addition, empowering organization's employees may also depend on their position such as whether they are regular staff, managers, etc. Therefore, it is suggested to do research based on organizational circumstances, culture as well as organizational structure.

\section{References}

Bhatnagar, J. (2007). Predictors of organizational commitment in India: strategic HR roles, organizational learning capability and psychological empowerment. The International Journal of Human Resource Management, 18(10), 1782-1811.

Corsun, D. L., \& Enz, C. A. (1999). Predicting psychological empowerment among service workers: The effect of support-based relationships. Human relations, 52(2), 205-224.

Egan, T. M., Yang, B., \& Bartlett, K. R. (2004). The effects of organizational learning culture and job satisfaction on motivation to transfer learning and turnover intention. Human resource development quarterly, 15(3), 279-301.

Laschinger, H. K. S., Finegan, J., Shamian, J., \& Wilk, P. (2001). Impact of structural and psychological empowerment on job strain in nursing work settings: expanding Kanter's model. Journal of nursing Administration, 31(5), 260-272.

Liden, R. C., Wayne, S. J., \& Sparrowe, R. T. (2000). An examination of the mediating role of psychological empowerment on the relations between the job, interpersonal relationships, and work outcomes. Journal of applied psychology,85(3), 407-416.

Huber, G. P. (1991). Organizational learning: The contributing processes and the literatures. Organization science, 2(1), 88-115.

Menon, S. T. (1999). Psychological empowerment: Definition, measurement, and validation. Canadian Journal of Behavioural Science/Revue canadienne des sciences du comportement, 31(3), 161.

Spreitzer, G. M. (1995). Psychological empowerment in the workplace: Dimensions, measurement, and validation. Academy of management Journal, 38(5), 1442-1465.

Spreitzer, G. M. (1996). Social structural characteristics of psychological empowerment. Academy of Management Journal, 39(2), 483-504.

Zhang, X., \& Bartol, K. M. (2010). Linking empowering leadership and employee creativity: The influence of psychological empowerment, intrinsic motivation, and creative process engagement. Academy of Management Journal, 53(1), 107-128.

Zimmerman, M. A., Israel, B. A., Schulz, A., \& Checkoway, B. (1992). Further explorations in empowerment theory: An empirical analysis of psychological empowerment. American Journal of Community Psychology, 20(6), 707-727.

Zimmerman, M. A. (1995). Psychological empowerment: Issues and illustrations. American Journal of Community Psychology, 23(5), 581-599. 